\title{
Degradation of dimethyl sulfoxide through fluidized-bed Fenton process: kinetic analysis
}

\author{
T.-C. Chen ${ }^{1}$ E. M. Matira ${ }^{2}$ - M.-C. Lu ${ }^{3}$ M. L. P. Dalida ${ }^{2}$
}

Received: 19 August 2015/Revised: 13 November 2015/Accepted: 13 December 2015/Published online: 17 February 2016 (C) Islamic Azad University (IAU) 2016

\begin{abstract}
In this study, fluidized-bed Fenton process (FBF) was used to degrade dimethyl sulfoxide (DMSO), one of the most widely used solvents. Oxidation by Fenton's reagent, $\mathrm{Fe}^{+2}$ and $\mathrm{H}_{2} \mathrm{O}_{2}$, is one of the cheapest advanced oxidation processes due to the high availability of the reagents. FBF is a modified approach that reduces the large amount of iron oxide sludge formed in conventional Fenton process. The optimal treatment efficiencies by FBF with $2 \mathrm{~h}$ of reaction were $95.22 \%$ of DMSO degradation and $34.38 \%$ of COD removal at the conditions of $5 \mathrm{mM} \mathrm{DMSO}, 68.97 \mathrm{~g} / \mathrm{L} \mathrm{SiO}_{2}$ carrier, $\mathrm{pH}_{\text {initial }}$ 3.0, $5 \mathrm{mM} \mathrm{Fe}^{2+}$, and $32.5 \mathrm{mM} \mathrm{H} \mathrm{H}_{2}$. The kinetic study was also done to investigate the two stages involved in the oxidation. The first stage fitted the zero reaction order with overall initial rate's apparent rate constant, $k_{1}$, of -0.099 . The second stage fitted the first order of DMSO degradation, with rate constant, $k_{2}$, of -0.0005 .
\end{abstract}

Keywords Fluidized-bed Fenton process - Dimethyl sulfoxide $\cdot$ Kinetic model

M.-C. Lu

mmclu@mail.cnu.edu.tw

1 Metal Industries Research and Development Centre, Kaohsiung 811, Taiwan

2 Department of Chemical Engineering, University of the Philippines Diliman, 1101 Quezon City, Philippines

3 Department of Environmental Resources Management, Chia Nan University of Pharmacy and Science, Tainan 717, Taiwan

\section{Introduction}

The growth of the thin-film-transistor liquid-crystal display (TFT-LCD) industry in recent years has made the treatment of its wastewater a serious concern. The organic materials in TFT-LCD wastewater such as dimethyl sulfoxide (DMSO), monoethanolamine (MEA), and tetramethylammonium hydroxide (TMAH) (Chen et al. 2003; Park et al. 2001; Urakami et al. 1990) cause the high COD concentration of the wastewater.

Dimethyl sulfoxide (DMSO) is a highly polar, highboiling, aprotic, water-miscible, organic liquid. It is a widely used solvent as it dissolves most aromatic and unsaturated organic compounds and many inorganic salts. It is miscible with other common organic solvents such as alcohols, esters, ketones, lower esters, chlorinated solvents, and aromatics (Chemical 2013). When the concentration of DMSO is at least $1000 \mathrm{mg} / \mathrm{L}$, it can be recycled and used in the original process. DMSO concentration higher than $24,600 \mathrm{mg} / \mathrm{L}$ is hazardous to fish and aquatic invertebrates, and $400 \mathrm{mg} / \mathrm{L}$ is toxic for aquatic plants. US EPA allows a discharge of less than $0.05 \mathrm{mg} / \mathrm{L}$ DMSO.

Physicochemical processes such as $\mathrm{UV} / \mathrm{H}_{2} \mathrm{O}_{2}$ (Lee et al. 2004) and ozone-based (Wu et al. 2007) processes have been evaluated for treating DMSO-containing wastewater, but these processes are not cost-effective when applied to fullscale operation. Anaerobic biodegradation of DMSO results in the formation of dimethyl sulfide (DMS), methane thiol (MT), and hydrogen sulfide $\left(\mathrm{H}_{2} \mathrm{~S}\right)$ which contribute to global warming and acid precipitation (Hwang et al. 2007). DMSO is not decomposed by aerobic biological treatment (Koito et al. 1998). Thus, biological treatment methods are not effective for treatment of wastewater that contains DMSO.

Advanced oxidation processes (AOPs) have been given attention as treatment methods for DMSO-containing 
wastewater as these are non-selective in attacking organic pollutants. AOPs generate hydroxyl radicals ( $\mathrm{HO}^{-}$), which are powerful non-selective oxidants that oxidize and mineralize almost all organic compounds into $\mathrm{CO}_{2}$ and inorganic ions (Brillas et al. 2009; Huang et al. 2009; Masomboon et al. 2009; Anotai et al. 2010). The Fenton process, a common AOP, uses hydrogen peroxide $\left(\mathrm{H}_{2} \mathrm{O}_{2}\right)$ and ferrous ions $\left(\mathrm{Fe}^{2+}\right)$ to produce radical $\mathrm{HO}$. In an acidic medium, this serial complex reaction generates radicals.

One of the cheapest kinds of AOPs is Fenton reaction. Large volume of iron oxide sludge is produced in the Fenton process and in subsequent neutralization process (Anotai et al. 2006).

Among the ozone-based oxidation processes on DMSO degradation, $\mathrm{O}_{3} / \mathrm{UV}$ was considered the most efficient as there was $76 \%$ of DMSO removal after $30 \mathrm{~min}$ and $64.6 \%$ of TOC removal after $5 \mathrm{~h}$ (Wu et al. 2007). For $\mathrm{UV} / \mathrm{H}_{2} \mathrm{O}_{2}$, Wu et al. (2007) observed that no TOC was removed even though there was $100 \%$ of DMSO removal after $3 \mathrm{~h}$ at pH 3. Lee et al. (2004) observed that $77.1 \%$ of TOC was removed after $4 \mathrm{~h}$; however, a very high molar ratio of $\mathrm{H}_{2} \mathrm{O}_{2}$ to DMSO (17.6) was used in the study.

Low DMSO degradation efficiency and high energy consumptions for $\mathrm{UV}$ and $\mathrm{O}_{3}$ were limitations in the UV/ $\mathrm{H}_{2} \mathrm{O}_{2}$ and $\mathrm{O}_{3} / \mathrm{UV}$. One of the improvements to manage this drawback is fluidized-bed Fenton oxidation which crystallizes iron oxides on the carrier in a fluidized-bed reactor (Chou et al. 2004; Muangthai et al. 2010).

The goal of this work was to determine the operating conditions leading to high DMSO removals from wastewaters using the fluidized-bed Fenton process. A detailed kinetic study performed in a batch reactor using the previously determined conditions was carried out. This study allowed a better understanding of the process and identification of practical aspects to consider in future works.

\section{Materials and methods}

\section{Materials}

Experiments for parametric and kinetic studies were conducted for $2 \mathrm{~h}$. All chemicals were purchased from Merck and Panreac companies. Solutions were prepared using deionized water from a Millipore system with resistivity of 18. $2 \mathrm{M} \Omega \mathrm{cm}$.

The fluidized-bed Fenton reactor (Fig. 1) has dimensions of $5.2 \mathrm{~cm}$ diameter and $140 \mathrm{~cm}$ height, contains perforated plate, 4-mm glass beads below the 2-mm glass beads at the bottom. A recirculation pump is attached, with $\mathrm{pH}$ probe and thermometer at the top. Sampling point was near the recirculation location. The reactor was loaded with

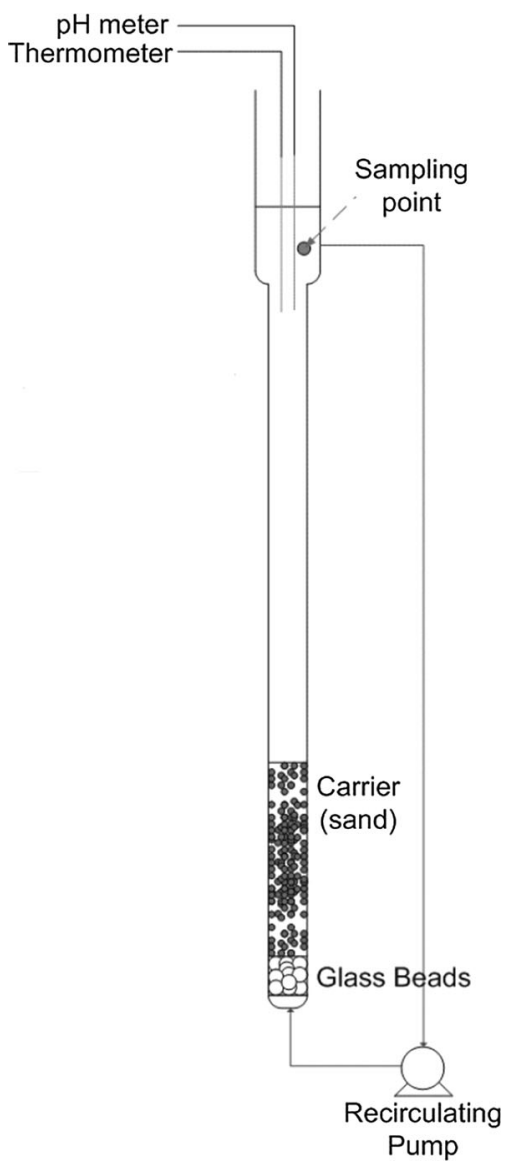

Fig. 1 Fluidized-bed Fenton reactor

$100 \mathrm{~g}$ of $0.42-0.50 \mathrm{~mm}$ sand as carriers $(0.42-0.50 \mathrm{~mm}$ sand was obtained using screen with Mesh 35 and 40).

\section{Experiment methods}

$1.45 \mathrm{ml}$ of DMSO was added into the reactor, followed by the desired amount of $\mathrm{FeSO}_{4} \cdot 7 \mathrm{H}_{2} \mathrm{O}$. Sampling was done before the start of the oxidation process and at specified intervals. The recirculation pump was adjusted such that the bed height of the carrier was maintained at $30 \mathrm{~cm}$ which was also equivalent to $360 \mathrm{~cm} / \mathrm{min}$ flow and 5.25 cycles per minute. The $\mathrm{pH}$ of the solution was then adjusted by adding $0.1 \mathrm{~N} \mathrm{NaOH}$ or $1 \mathrm{~N} \mathrm{H}_{2} \mathrm{SO}_{4}$ into the reactor. Addition of $\mathrm{H}_{2} \mathrm{O}_{2}$ started the Fenton reaction process.

\section{Analysis methods}

The spectrophotometric analysis of hydrogen peroxide concentrations and ferrous ion concentrations were done by Thermo Spectronic Genesys 20 with complexing samples of potassium titanium oxalate $\left(\mathrm{K}_{2} \mathrm{Ti}\left(\mathrm{C}_{2} \mathrm{O}_{4}\right)\right)$ and 1,10 phenanthroline, respectively. Absorbance was measured at wavelengths of $400 \mathrm{~nm}$ and $510 \mathrm{~nm}$ for analyses of $\mathrm{H}_{2} \mathrm{O}_{2}$ 
and $\mathrm{Fe}^{2+}$ concentrations, respectively. DMSO concentrations were detected by a high-performance liquid chromatography (HPLC) with Spectra SYSTEM model SN4000 and Asahipak ODP, 506D column $(150 \mathrm{~mm} \times$ $6 \mathrm{~mm} \times 5 \mathrm{~mm}$ ) using $40 \%$ acetonitrile as mobile phase. $\mathrm{COD}$ was measured using closed-reflux titrimetric method based on the standard methods (APHA).

\section{Results and discussion}

\section{Effect of initial pH}

The effect of initial $\mathrm{pH}$ on real DMSO wastewater treatment in terms of DMSO removal efficiency by FB-Fenton process was investigated as Fenton oxidation is a highly $\mathrm{pH}$-dependent process. Solution $\mathrm{pH}$ is a significant parameter of the $\mathrm{HO}$ generation in the Fenton reaction (Anotai et al. 2011; Kochany and Lugowski 1998; Muruganandham and Swaminathan 2004; Tang and Huang 1996a, b; Tang and Tassos 1997).

Generally, Fenton process is conducted in acidic medium. In the previous studies, the increase in $\mathrm{pH}$ during the Fenton process leads to coagulation whereby pollutants are removed by complexation of reactions due to the conversion of $\mathrm{Fe}^{2+}$ and $\mathrm{Fe}^{3+}$ to $\mathrm{Fe}(\mathrm{OH})_{n}$ type structures (Mollah et al. 2001).

Compared to $\mathrm{pH} 3$, initial $\mathrm{pH} 2$ was an inferior condition as it only led to $82.02 \%$ of DMSO degradation. The lower degradation efficiency could be due to $\mathrm{Fe}^{2+}: \mathrm{H}_{2} \mathrm{O}_{2}$ complex formation with low $\mathrm{pH}$ value. Reaction of $\mathrm{H}_{2} \mathrm{O}_{2}$ and $\mathrm{Fe}^{2+}: \mathrm{H}_{2} \mathrm{O}_{2}$ complex produces $\mathrm{HO}$ at a very slow rate (Bigda 1995; Lin and Lo 1997). Indeed, these formations of complexes reduce the amount of free $\mathrm{Fe}^{2+}$, thus generation of hydroxyl radical as well as degradation of DMSO decreased.

At initial $\mathrm{pH}$ values of 4 and 7, oxidation efficiency was decreased, and the DMSO degradation was only 80.78 and $39.58 \%$, respectively. This could mean that the $\mathrm{Fe}^{2+}: \mathrm{OH}^{-}$ complex was formed at higher $\mathrm{pH}$ value. This complex used up $\mathrm{Fe}^{2+}$; hence, there was limited $\mathrm{Fe}^{2+}$ for $\mathrm{HO}^{-}$production from $\mathrm{H}_{2} \mathrm{O}_{2}$ (Bigda 1995; Lin and Lo 1997). Different $\mathrm{pH}$ values between 2 and 7 were evaluated. The result showed that the optimal efficiency was reached at $95.22 \%$ of DMSO degradation when the initial $\mathrm{pH}$ value was 3.0 with 2-h reaction time. In this study, $\mathrm{pH} 3.0$ was the optimal value for further parametric investigation and kinetic study (Fig. 2a). The important phenomenon observed is that the solution $\mathrm{pH}$ changed after $120 \mathrm{~min}$ of reaction. The initial solution $\mathrm{pH}$ was 3.0, and the solution $\mathrm{pH}$ after $120 \mathrm{~min}$ of reaction decreased slightly. However, the solution $\mathrm{pH}$ varied significantly at the initial $\mathrm{pH}$ of 2.1 (Fig. 2b). This is because $\mathrm{HO}^{\circ}$ attacked DMSO, and then,
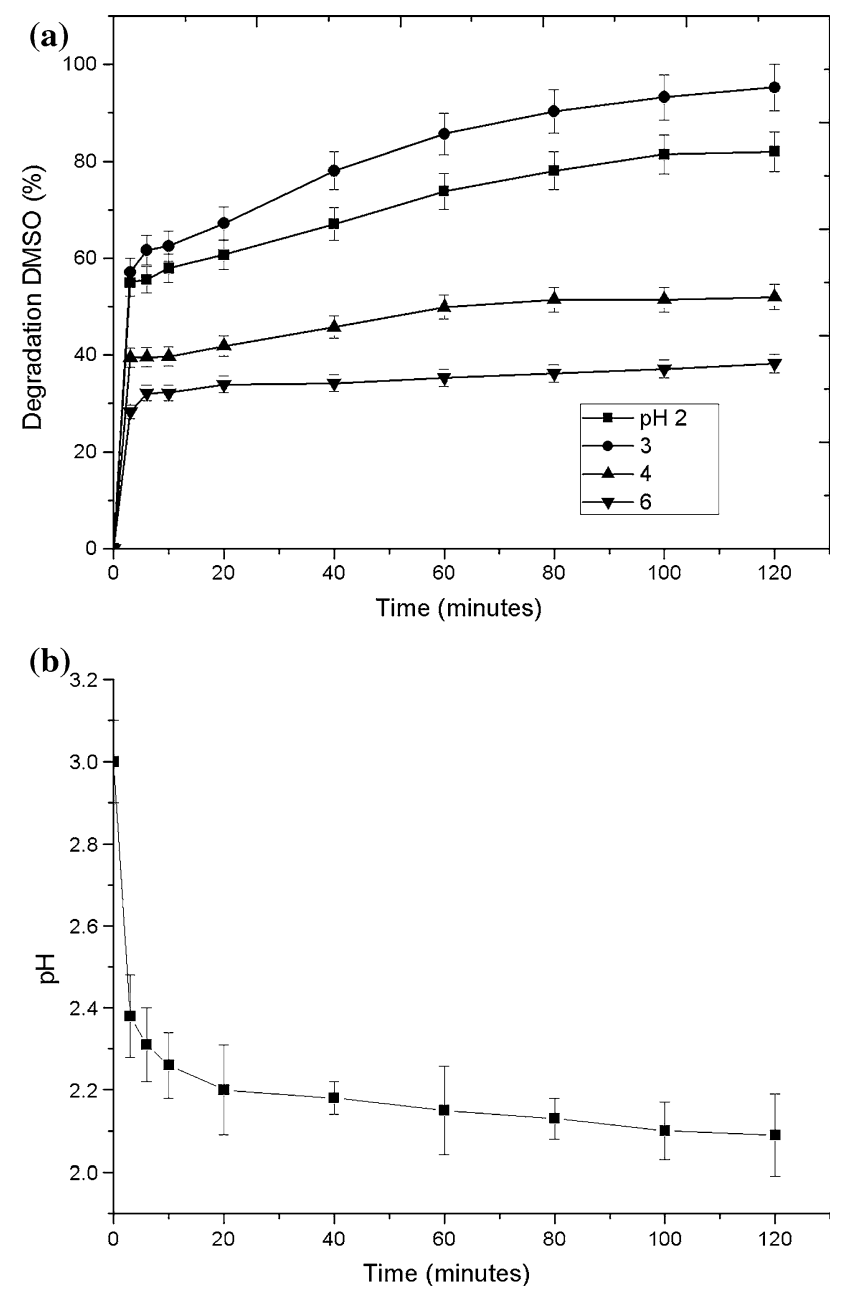

Fig. 2 a Effect of different pH on DMSO degradation efficiency. b The $\mathrm{pH}$ values after $120 \mathrm{~min}$ of fluidized-bed Fenton reaction

$\mathrm{H}^{+}$concentration increased. Therefore, the $\mathrm{pH}$ value after reaction decreased.

\section{Effect of initial $\mathrm{Fe}^{2+}$ concentration}

An important factor in the electro-Fenton process is a suitable $\mathrm{Fe}^{2+}$ concentration (Zhou et al. 2007). The concentration of $\mathrm{HO}^{-}$radical, the main oxidizing agent in the Fenton process, increases with increase in $\mathrm{Fe}^{2+}$ concentration, and thus, efficiency of the Fenton process increases with increase in $\mathrm{Fe}^{2+}$ concentration. The presence of $\mathrm{Fe}^{2+}$ significantly improved the COD removal efficiency. The COD removal percentage increased from 19.8 to $43.1 \%$ by externally adding a $\mathrm{Fe}^{2+}$ concentration of $0.33 \mathrm{mM}$ (Wang et al. 2010). In can be seen from Fig. 3a that $\mathrm{H}_{2} \mathrm{O}_{2}$ consumption increased as the initial $\mathrm{Fe}^{2+}$ increased. Scavenging of hydroxyl radicals, which is indicated by negative effect of $\mathrm{Fe}^{2+}$ concentration, was not observed in all of the $\mathrm{Fe}^{2+}$ dosage when based on DMSO degradation 
after $2 \mathrm{~h}$. However, as can be seen in Fig. 3b, based on initial rates, the scavenging of hydroxyl radicals was present at initial $\left[\mathrm{Fe}^{2+}\right]$ of $7.25 \mathrm{mM}$. This showed that a high $\mathrm{Fe}^{2+}$ concentration in FB-Fenton process did not increase DMSO degradation due to the $\mathrm{Fe}^{2+}$ ions competing against the reacted molecules for $\mathrm{HO}^{\circ}$, as expressed in Eq. (4).

Since the application of $5 \mathrm{mM} \mathrm{Fe}^{2+}$ led to appreciable DMSO degradation in $2 \mathrm{~h}$, this dosage was considered instead of $7.25 \mathrm{mM}$ in succeeding investigation. This is also for lower cost in case the study will be used for future industrial application.

\section{Effect of initial $\mathrm{H}_{2} \mathrm{O}_{2}$ concentration}

Increasing the amount of $\mathrm{H}_{2} \mathrm{O}_{2}$ improves the Fenton process performance, although the excess amount may cause scavenging of hydroxyl radicals as shown in Eqs. (1)-(2). Equation (3) is a recombination of hydroxyl radicals rather than scavenging. $\mathrm{Fe}^{2+}$ loading has the same effect as it also

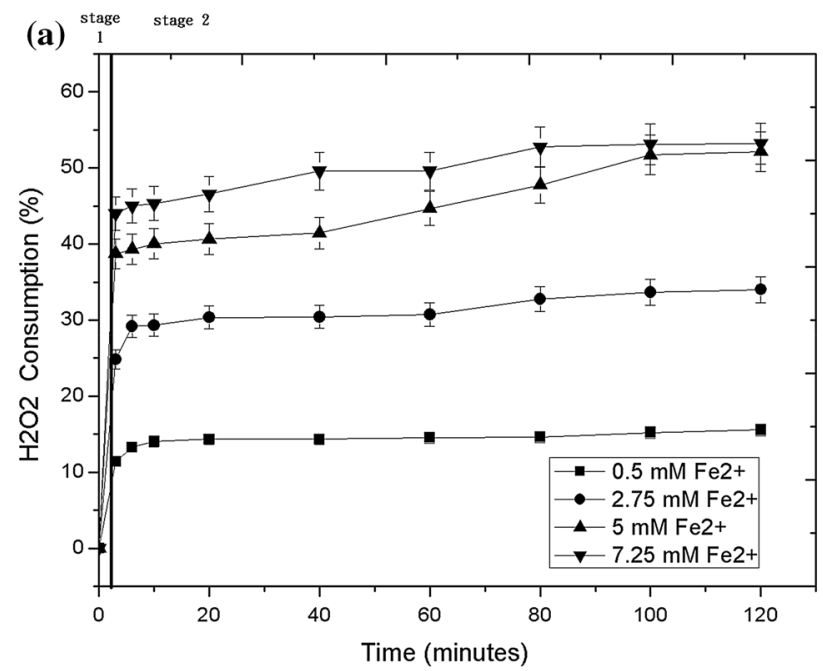

(b)

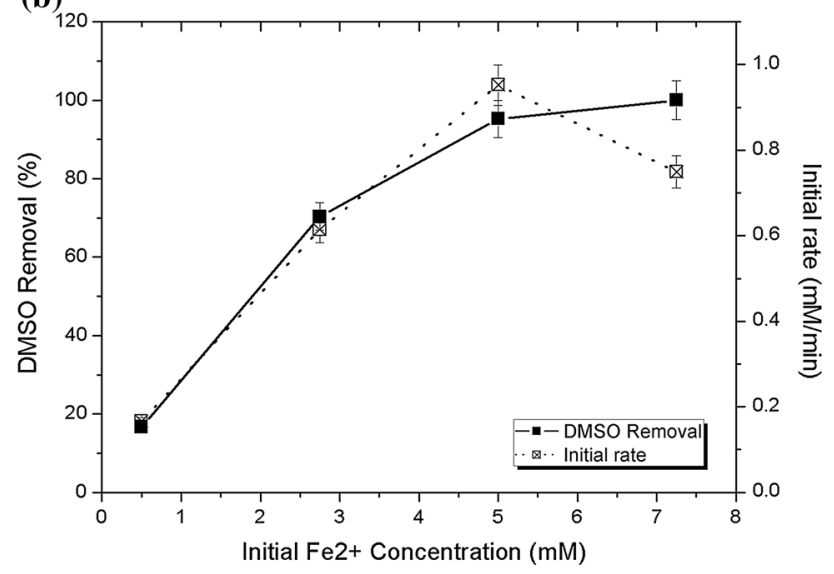

Fig. 3 Effect of initial $\mathrm{Fe}^{2+}$ concentration: a $\mathrm{H}_{2} \mathrm{O}_{2}$ consumption b DMSO removal after $2 \mathrm{~h}$ when initial conditions were $\mathrm{pH} 3$, $32.5 \mathrm{mM}$ of $\mathrm{H}_{2} \mathrm{O}_{2}$, and $5 \mathrm{mM}$ of DMSO enhances the degradation efficiency but scavenge hydroxyl radicals when in excess amount, as shown in Eq. (4).

$$
\begin{aligned}
& \mathrm{H}_{2} \mathrm{O}_{2}+\mathrm{HO}^{\circ} \rightarrow \mathrm{H}_{2} \mathrm{O}+\mathrm{HO}_{2} \quad k=2.7 \times 10^{7} \mathrm{M}^{-1} \mathrm{~s}^{-1} \\
& \mathrm{HO}_{2}+\mathrm{HO}^{\circ} \rightarrow \mathrm{H}_{2} \mathrm{O}+\mathrm{O}_{2} \quad k=1.0 \times 10^{10} \mathrm{M}^{-1} \mathrm{~s}^{-1} \\
& \mathrm{HO}^{\circ}+\mathrm{HO}^{\circ} \rightarrow \mathrm{H}_{2} \mathrm{O}_{2} \quad k=4.2 \times 10^{9} \mathrm{M}^{-1} \mathrm{~s}^{-1} \\
& \mathrm{Fe}^{2+}+\mathrm{HO}^{\circ} \rightarrow \mathrm{Fe}^{3+}+\mathrm{OH}^{-} \quad k=3.0 \times 10^{8} \mathrm{M}^{-1} \mathrm{~s}^{-1}
\end{aligned}
$$

According to the finding of Ting et al. (2009) and Methatham et al. (2012), the initial concentration of $\mathrm{H}_{2} \mathrm{O}_{2}$ played an important role in the Fenton process. Removal of COD increased with an increase in $\mathrm{H}_{2} \mathrm{O}_{2}$ concentration. The increase in the removal efficiency was due to the increase in $\mathrm{HO}^{\circ}$ radical concentration as a result of the addition of $\mathrm{H}_{2} \mathrm{O}_{2}$ (Ting et al. 2009). Zhang et al. (2007) stated that efficiency of hydrogen peroxide for removing organic materials in the leachate decreased with the increase in Fenton's reagent dosage. At a high concentration of $\mathrm{H}_{2} \mathrm{O}_{2}$, the decrease in removal efficiency was due to the hydroxyl radical scavenging effect of $\mathrm{H}_{2} \mathrm{O}_{2}$ and the recombination of the hydroxyl radical (Muruganandham and Swaminathan 2004).

From our previous research result (Bellotindos et al. 2014), the hydrogen peroxide efficiency decreased as $\mathrm{H}_{2} \mathrm{O}_{2}$ dosage increased, although DMSO degradation improved when $\mathrm{H}_{2} \mathrm{O}_{2}$ dosage increased to $60 \mathrm{mM}$. This could mean that the $5 \mathrm{mM} \mathrm{Fe}^{2+}$ dosage is a limiting reagent. Thus, the scavenging effect of the excess $\mathrm{H}_{2} \mathrm{O}_{2}$ was evident.

An appreciable DMSO removal was obtained at $\mathrm{H}_{2} \mathrm{O}_{2}$ dosage of $32.5 \mathrm{mM}$ and $60 \mathrm{mM}$. At higher $\mathrm{H}_{2} \mathrm{O}_{2}$ concentration, DMSO removal efficiency increased only by $2 \%$. In this study, the scavenging effect of $\mathrm{H}_{2} \mathrm{O}_{2}$ (Anotai et al. 2009) was observed when the initial $\mathrm{H}_{2} \mathrm{O}_{2}$ was at least $60 \mathrm{mM}$. For further investigation, the $\mathrm{H}_{2} \mathrm{O}_{2}$ concentration used was $32.5 \mathrm{mM}$.

\section{Degradation mechanism for DMSO}

In our previous study, the oxidation intermediates of DMSO, namely methanesulfinate, formaldehyde, and formate, were detected (Matira et al. 2015). Wu et al. (2007) also reported that there are two groups of intermediates in the degradation of DMSO: the sulfur-containing compounds and the non-sulfur-containing compounds.

Two primary intermediates are formaldehyde (HCHO) and methanesulfinate $\left(\mathrm{CH}_{3} \mathrm{SO}^{2-}\right)$. Formaldehyde is further degradable to formate $\left(\mathrm{HCOO}^{-}\right)$and then to carbon dioxide. Meanwhile, methanesulfinate is degradable to formaldehyde and to methanesulfonate $\left(\mathrm{CH}_{3} \mathrm{SO}^{3-}\right)$. Methanesulfonate is then degradable to sulfate (Lee et al. 2004). Methanesulfonate, however, was the most resistant intermediate to degrade. The optimal COD removal 
efficiency is also shown in Table 1 . It can be seen that it is necessary to add more oxidant and extending the reaction time for decreasing the COD further.

\section{Kinetics of DMSO degradation during fluidized-bed Fenton process}

The fluidized-bed Fenton oxidation process has two stages of reaction ( $\mathrm{Lu}$ et al. 1999). Thus, two kinetic equations were generated in this study. In Fig. 3a, the first stage was based on zero order assuming there were no intermediates yet present during this period. Time 0-3 min was considered for initial rates. For the second stage of oxidation, reaction intermediates were already present as well as reaction mechanisms involved in the fluidized-bed reactor (Matira et al. 2015). To simplify the study, overall kinetic equation generated was based on the degradation of DMSO. Linear plots were generated according to zero, first, and second orders of reaction. The reaction order that had the best fit for the process was determined. Time 3-120 min was considered for this stage.

Least mean square method was used for determining the rate constants for the first and second stages of oxidation in terms of initial concentrations of $\mathrm{Fe}^{2+}, \mathrm{H}_{2} \mathrm{O}_{2}$, and DMSO.

The DMSO degradation using FB-Fenton process could be described by two separate stages. The first stage of the degradation is the homogenous stage, which is also the $\mathrm{Fe}^{2+} / \mathrm{H}_{2} \mathrm{O}_{2}$ stage where there are abundant of hydroxyl radicals (Lu et al. 1999). The second stage of degradation is combination of (1) homogenous $\mathrm{Fe}^{3+/} \mathrm{H}_{2} \mathrm{O}_{2}$ which slowly produces hydroxyphenol radicals $\left(\mathrm{H}_{2} \mathrm{O}\right)$ and $\mathrm{Fe}^{2+}$ wherein $\mathrm{Fe}^{2+}$ then catalyzes hydroxyl radical production from $\mathrm{H}_{2} \mathrm{O}_{2}$
(Lu et al. 1999), and (2) heterogeneous Fenton or Fentonlike process that utilizes the surface of iron ions $\left[\mathrm{Fe}(\mathrm{OH})_{2}\right]^{2+},\left[\mathrm{Fe}\left(\mathrm{H}_{2} \mathrm{O}\right)\right]^{2+},\left[\mathrm{Fe}\left(\mathrm{H}_{2} \mathrm{O}\right)_{6}\right]^{3+},\left[\mathrm{Fe}_{2}(\mathrm{OH})_{2}\right]^{4+}$, ferrous polycation, $\mathrm{Fe}_{2} \mathrm{O}_{3}$, and $\alpha$-FeOOH in iron oxide catalyst to produce hydroxyl radicals from $\mathrm{H}_{2} \mathrm{O}_{2}$ (Soon and Hameed 2011). Since hydroxyl radical with $\mathrm{E}^{\circ}=2.80 \mathrm{~V} /$ SHE is a much stronger oxidant than hydroxyphenol radical with oxidizing potential at 1.65 V/SHE (Brillas et al. 2009), hydroxyl radical was still considered as the governing oxidant in the second stage of Fenton process. Furthermore, adsorption or complexation of DMSO with generated iron oxides is considered negligible, as DMSO cannot form complexes with iron or other metal ions (Tai et al. 2004).

The kinetic equations' rate constants, patterned after Anotai et al. (2009), used the least mean square method in determining the rate law for initial degradation rates. For this research, the least mean square method was used in generating both the rate constants of the kinetic equations for the first and second stages of the oxidation process.

\section{Kinetics during the first stage of fluidized-bed Fenton process}

The $\mathrm{Fe}^{2+} / \mathrm{H}_{2} \mathrm{O}_{2}$ stage for the FB-Fenton degradation process was short because the $\mathrm{Fe}^{2+}$ easily transformed to $\mathrm{Fe}^{3+}$. The stage occurred only from start to $3 \mathrm{~min}$. During this period, the intermediates have a negligible effect on the degradation of DMSO. Due to abundance of hydroxyl radicals, the reaction can be considered zero order which means that the degradation is independent on the instantaneous concentrations of reactants and intermediates. Thus, initial rates were determined using linear regression

Table 1 Effects of initial conditions namely $\mathrm{pH},\left[\mathrm{Fe}^{2+}\right],\left[\mathrm{H}_{2} \mathrm{O}_{2}\right]$, and [DMSO] on the degradation of DMSO in fluidized-bed Fenton process

\begin{tabular}{|c|c|c|c|c|c|c|c|c|c|}
\hline \multirow{2}{*}{$\begin{array}{l}\text { Studied } \\
\text { variable }\end{array}$} & \multicolumn{3}{|c|}{ Experimental condition } & \multirow{2}{*}{$\begin{array}{l}\text { Initial rate } \\
(\mathrm{mM} / \mathrm{min}) \\
(0-3 \mathrm{~min})\end{array}$} & \multirow{2}{*}{$\begin{array}{l}\text { Slope of } \log \text { of } \\
\text { (reagent) versus } \log \text { of } \\
\text { initial rate for reaction } \\
\text { order }\end{array}$} & \multirow{2}{*}{$\begin{array}{l}\text { Rate } \\
\text { constant } \\
(1 / \mathrm{min}) \\
(3-120 \\
\text { min })\end{array}$} & \multirow{2}{*}{$\begin{array}{l}\text { Slope of } \log \text { of } \\
\text { (reagent) versus } \log \text { of } \\
\text { rate constant for } \\
\text { reaction order }\end{array}$} & \multirow{2}{*}{$\begin{array}{l}\text { Total } \\
\text { DMSO } \\
\text { removal } \\
(\%)\end{array}$} & \multirow{2}{*}{$\begin{array}{l}\text { COD } \\
\text { removal } \\
(\%)\end{array}$} \\
\hline & $\begin{array}{l}{\left[\mathrm{Fe}^{2+}\right]} \\
(\mathrm{mM})\end{array}$ & $\begin{array}{l}{\left[\mathrm{H}_{2} \mathrm{O}_{2}\right]} \\
(\mathrm{mM})\end{array}$ & $\begin{array}{l}{[\mathrm{DMSO}]} \\
(\mathrm{mM})\end{array}$ & & & & & & \\
\hline \multirow[t]{4}{*}{$\mathrm{Fe}^{2+}$} & 0.50 & 32.50 & 5.00 & 0.17 & $0.760^{\mathrm{a}}$ & 0.0006 & $1.472^{\mathrm{a}}$ & 16.66 & \\
\hline & 2.75 & & & 0.61 & & 0.0064 & & 70.34 & \\
\hline & 5.00 & & & 0.95 & & 0.0188 & & 95.22 & 34.38 \\
\hline & 7.25 & & & 0.75 & & 0.0382 & & $>99.00$ & \\
\hline \multirow[t]{4}{*}{$\mathrm{H}_{2} \mathrm{O}_{2}$} & 5.00 & 5.00 & 5.00 & 0.43 & $0.363^{\mathrm{b}}$ & 0.0032 & $0.808^{\mathrm{b}}$ & 51.83 & \\
\hline & & 32.50 & & 0.95 & & 0.0188 & & 95.22 & 34.38 \\
\hline & & 60.00 & & 1.00 & & 0.0215 & & 96.82 & \\
\hline & & 87.50 & & 0.81 & & 0.0064 & & 76.88 & \\
\hline \multirow[t]{3}{*}{ DMSO } & 5.00 & 32.50 & 5.00 & 0.95 & -0.218 & 0.0188 & -1.123 & 95.22 & 34.38 \\
\hline & & & 10.00 & 1.06 & & 0.0060 & & 67.61 & \\
\hline & & & 50.00 & 0.59 & & 0.0013 & & 16.04 & \\
\hline
\end{tabular}

a The degradation at $7.25 \mathrm{mM}$ of $\mathrm{Fe}^{2+}$ was not considered in kinetic study as there was scavenging effect during initial stage

b Degradation at $87.5 \mathrm{mM}$ of $\mathrm{H}_{2} \mathrm{O}_{2}$ was not used since the initial rate and rate constant decreased afterward as the $\mathrm{H}_{2} \mathrm{O}_{2}$ was in excess 

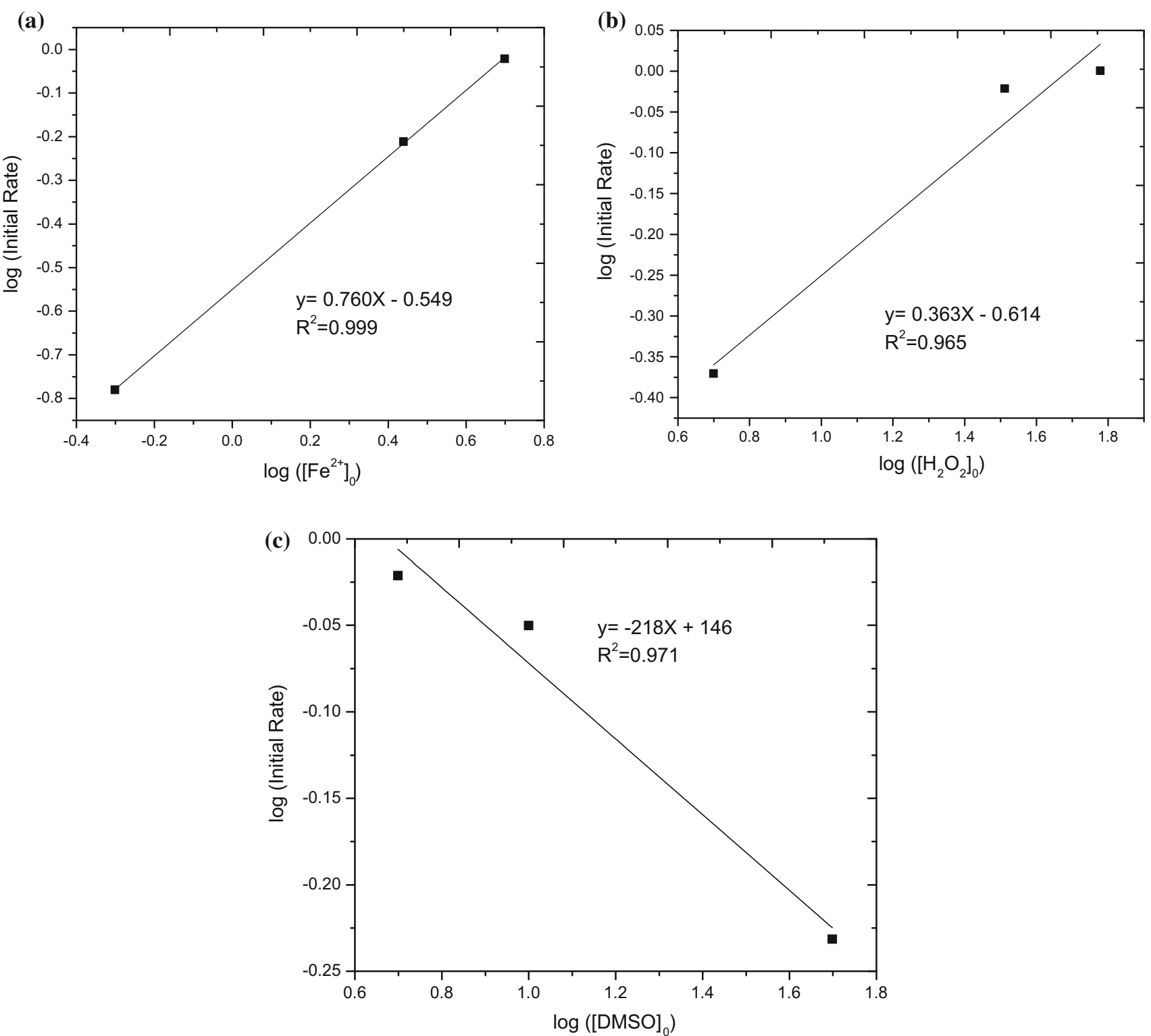

Fig. 4 Linear plots to determine $\mathrm{n}$ values for initial rate constants when initial conditions are $\mathrm{pH} 3.0,5 \mathrm{mM}$ of DMSO, $5 \mathrm{mM}$ of Fe ${ }^{2+}$, and $32.5 \mathrm{mM}$ of $\mathrm{H}_{2} \mathrm{O}_{2}$

of $\log -\log$ plots wherein $x$-values are the $\log$ of initial concentrations of reagents and $y$-values are the $\log$ of corresponding initial DMSO degradation rates.

The initial rates of DMSO degradation can be calculated by Eqs. (5) and (6) wherein $k_{1 \text {,reagent }}$ is the individual $x$ reagent's apparent constant, $k_{1}$ is the overall apparent constant, and $n$ is the slope of the log-log plot for initial rates.

$\frac{\mathrm{d}[\mathrm{DMSO}]}{\mathrm{d} t}=-k_{1}$, reagent $[\text { Reagent }]_{0}^{n}$

$\frac{\mathrm{d}[\mathrm{DMSO}]}{\mathrm{d} t}=-k_{1}\left[\text { Reagent }_{1}\right]_{0}^{n_{1}} \ldots \ldots\left[\text { Reagent }_{x}\right]_{0}^{n_{x}}$
Figure 4 shows the linear plots to determine the $n$ values. It can be seen that the log-log plot between initial rates and initial reagent concentrations generated lines with high $R$-square values, from 0.965 to 0.999 .

Using the slopes obtained in the linear regressions, shown in Fig. 5 and listed in Table 1, initial rates can be calculated from Eqs. (7) to (9).

$\frac{\mathrm{d}[\mathrm{DMSO}]}{\mathrm{d} t}=-k_{1}, \mathrm{Fe}^{2+}\left[\mathrm{Fe}^{2+}\right]_{0}^{0.760}$
$\frac{\mathrm{d}[\mathrm{DMSO}]}{\mathrm{d} t}=-k_{1}, \mathrm{H}_{2} \mathrm{O}_{2}\left[\mathrm{H}_{2} \mathrm{O}_{2}\right]_{0}^{0.363}$ 

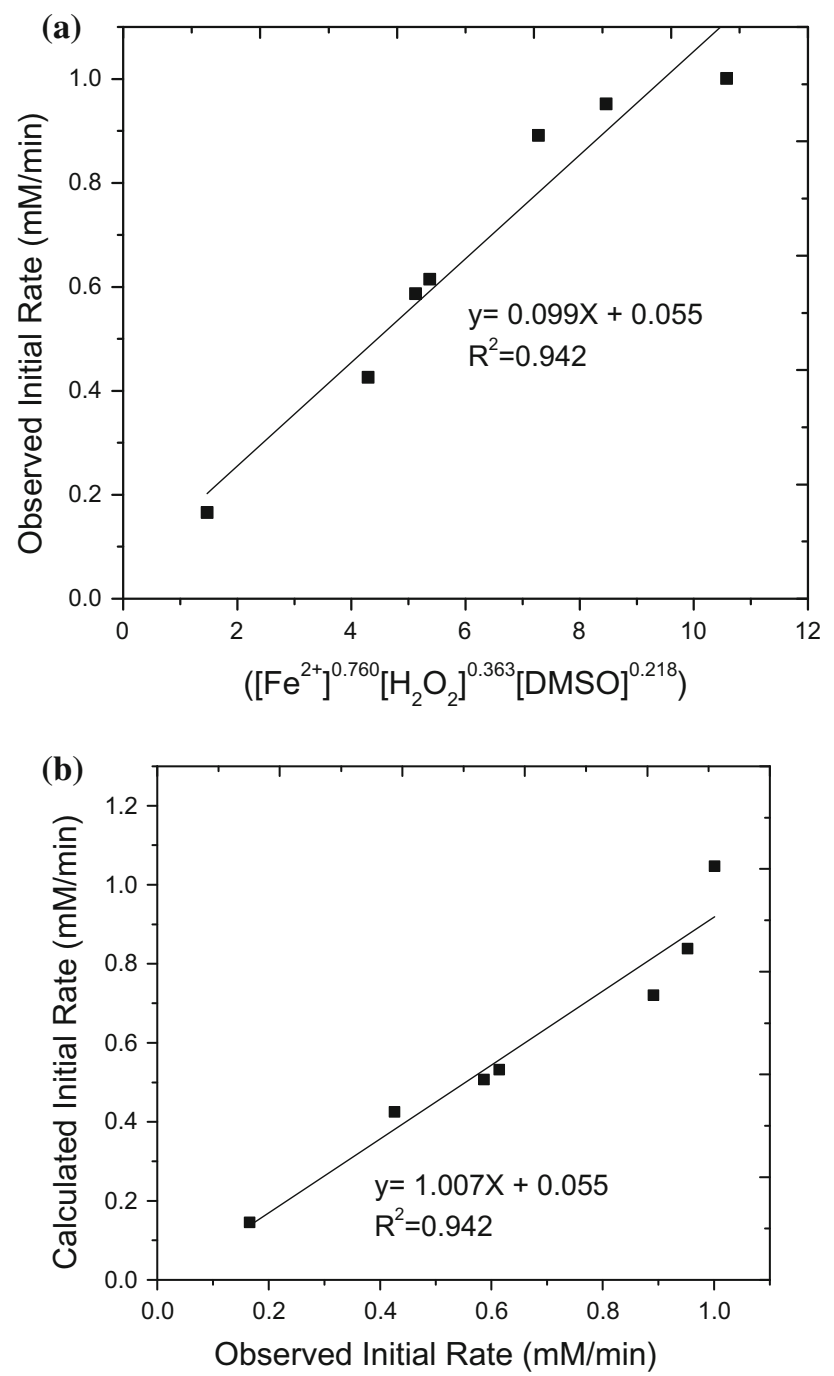

Fig. 5 a Relationship between observed and calculated initial rates of DMSO oxidation when initial conditions were $\mathrm{pH} 3,0.5-5 \mathrm{mM}$ of $\mathrm{Fe}^{2+}, 5-60 \mathrm{mM}$ of $\mathrm{H}_{2} \mathrm{O}_{2}$, and $5-50 \mathrm{mM}$ of DMSO. b Linear regression test for degradation of $5 \mathrm{mM}$ DMSO when initial conditions were $\mathrm{pH} 3,5 \mathrm{mM}$ of $\mathrm{Fe}^{2+}$, and $32.5 \mathrm{mM}$ of $\mathrm{H}_{2} \mathrm{O}_{2}$

$\frac{\mathrm{d}[\mathrm{DMSO}]}{\mathrm{d} t}=k_{1, \mathrm{DMSO}} \frac{1}{[\mathrm{DMSO}]_{0}^{0.218}}$

Since the reaction order of each individual component was known, overall degradation kinetics in terms of initial rates is presented in Eq. (10). Overall apparent initial rate's apparent rate constant, $k_{1}$, is -0.099 and was obtained by using the least squares method which minimized the sum of error squares between the observed initial rate or rate constant of DMSO degradation and the calculated initial rate generated (shown in Fig. 5a).

$\frac{\mathrm{d}[\mathrm{DMSO}]}{\mathrm{d} t}=-0.099 \frac{\left[\mathrm{Fe}^{2+}\right]_{0}^{0.760}\left[\mathrm{H}_{2} \mathrm{O}_{2}\right]_{0}^{0.363}}{[\mathrm{DMSO}]_{0}^{0.218}}$

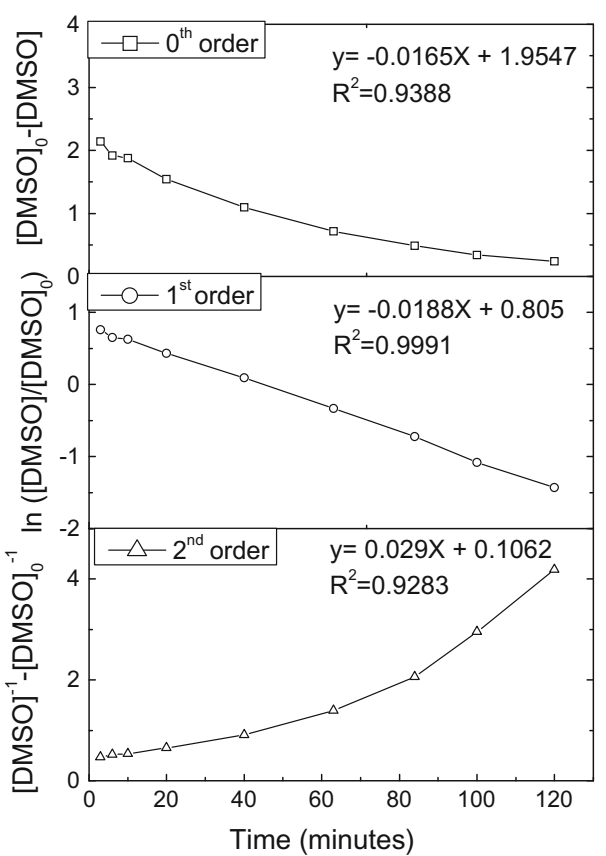

Fig. 6 Linear regression testing for three reaction orders (zero, first, and second orders) on the batch that has the highest efficiency among the considered runs of DMSO degradation

The observed initial rate versus calculated initial rates using Eq. (6) were graphed. The result showed linear regression with slope of 1.007 and $R^{2}$ of 0.946 , shown in Fig. 5b.

\section{Kinetics during the second stage of fluidized-bed Fenton process}

The second stage or the $\mathrm{Fe}^{3+} / \mathrm{H}_{2} \mathrm{O}_{2}$ stage of the Fenton degradation process ( $\mathrm{Lu}$ et al. 1999) occurred from time 3 to $120 \mathrm{~min}$. DMSO degradation during this period of reaction was checked for linear fitting based on three different reaction orders (zero, first, and second orders).

Figure 6 is the linear regression testing for different reaction orders (zero, first, and second orders) on the batch that has the highest efficiency among the considered runs of DMSO degradation in the study. The result showed that the R-squares were 0.9388, 0.9991, and 0.9283 in these three different reaction orders and the first-order kinetics was the best fit.

Based on Table 2, the first-order reaction has the highest $R$-square in each experimental reaction. Thus, the $\mathrm{Fe}^{3+} /$ $\mathrm{H}_{2} \mathrm{O}_{2}$ stage is considered following the first-order kinetics. Thus, for pseudo-first-order kinetics, the following Eq. (11) could describe the reaction rates:

$\frac{\mathrm{d}[\mathrm{MDSO}]}{\mathrm{d} t}=-k[\mathrm{DMSO}]$ 
Table $2 R$-squared values for linear regression testing for the DMSO degradation rate that occurred in time 3-120 min

\begin{tabular}{|c|c|c|c|c|c|c|}
\hline \multirow[t]{2}{*}{ Studied variable } & \multicolumn{3}{|c|}{ Experimental condition } & \multicolumn{3}{|c|}{$R$-square value from linear regression } \\
\hline & {$\left[\mathrm{Fe}^{2+}\right](\mathrm{mM})$} & {$\left[\mathrm{H}_{2} \mathrm{O}_{2}\right](\mathrm{mM})$} & {$[\mathrm{DMSO}](\mathrm{mM})$} & Zero-order kinetics & First-order kinetics & Second-order kinetics \\
\hline \multirow[t]{3}{*}{$\mathrm{Fe}^{2+}$} & 0.50 & 32.50 & 5.00 & 0.714 & 0.718 & 0.722 \\
\hline & 2.75 & & & 0.964 & 0.983 & 0.983 \\
\hline & 5.00 & & & 0.938 & 0.999 & 0.928 \\
\hline \multirow[t]{3}{*}{$\mathrm{H}_{2} \mathrm{O}_{2}$} & 5.00 & 5.00 & 5.00 & 0.905 & 0.933 & 0.950 \\
\hline & & 32.50 & & 0.938 & 0.999 & 0.928 \\
\hline & & 60.00 & & 0.930 & 0.999 & 0.884 \\
\hline \multirow[t]{3}{*}{ DMSO } & 5.00 & 32.50 & 5.00 & 0.958 & 0.999 & 0.928 \\
\hline & & & 10.00 & 0.991 & 0.965 & 0.918 \\
\hline & & & 50.00 & 0.982 & 0.984 & 0.986 \\
\hline
\end{tabular}

To determine the value of $\mathrm{k}$, the procedure for the first stage was used in determining the constants for the kinetics. The pseudo-first-order rate of DMSO degradation can be represented using Eqs. (12) and (13) wherein $k_{2 \text {,reagent }}$ is the individual $x$ reagent's apparent constant, $k_{2}$ is the overall apparent constant, and $\mathrm{m}$ is the slope of the $\log \left([\text { Reagent }]_{0}\right)-\log ($ rate constant $)$ plot.

$\frac{\mathrm{d}[\mathrm{DMSO}]}{\mathrm{d} t}=-k_{2}$, reagent $[\text { Reagent }]_{0}^{m}[\mathrm{DMSO}]$

$\frac{\mathrm{d}[\mathrm{DMSO}]}{\mathrm{d} t}=-k_{2}\left[\text { Reagent }_{1}\right]_{0}^{m_{1}} \cdots\left[\text { Reagent }_{x}\right]_{0}^{m_{x}}[\mathrm{DMSO}]$

The log-log plot between rate constants and initial reagent concentrations generated lines with high $R$-square values from 0.969 to 0.996 (shown in Fig. 7a-c). Thus, this shows that DMSO degradation is a pseudo-first order reaction. Generally, the treatment of organic wastewaters such as municipal and textile wastewaters fitted well for pseudo-firstorder (Karthikeyan et al. 2013; Soon and Hameed 2011).

Using the slopes in the linear regressions, shown in Fig. $7 \mathrm{a}-\mathrm{c}$ and listed in Table 2, first-order rates can be calculated from Eqs. (14) to (16).

$$
\begin{aligned}
& \frac{\mathrm{d}[\mathrm{DMSO}]}{\mathrm{d} t}=-k_{2}, \mathrm{Fe}^{2+}\left[\mathrm{Fe}^{2+}\right]_{0}^{1.472}[\mathrm{DMSO}] \\
& \frac{\mathrm{d}[\mathrm{DMSO}]}{\mathrm{d} t}=-k_{2}, \mathrm{H}_{2} \mathrm{O}_{2}\left[\mathrm{H}_{2} \mathrm{O}_{2}\right]_{0}^{0.808}[\mathrm{DMSO}] \\
& \frac{\mathrm{d}[\mathrm{DMSO}]}{\mathrm{d} t}=k_{2}, \mathrm{DMSO} \frac{1}{[\mathrm{DMSO}]_{0}^{1.123}}[\mathrm{DMSO}]
\end{aligned}
$$

Since the reaction order of each individual component was known, overall degradation kinetics was determined in linear plot (Fig. 7d) and presented in Eq. (17). Overall apparent initial rate's apparent rate constant, $k_{2}$, is -0.0005 .

The plot of observed versus calculated rate pseudofirst-order constants using Eq. (4.14) depicts the linear regression with slope of 0.968 and $R^{2}$ of 0.945 , shown in Fig. 7e.

$\frac{\mathrm{d}[\mathrm{DMSO}]}{\mathrm{d} t}=-0.0005 \frac{\left[\mathrm{Fe}^{2+}\right]_{0}^{1.472}\left[\mathrm{H}_{2} \mathrm{O}_{2}\right]_{0}^{0.808}}{[\mathrm{DMSO}]_{0}^{1.123}}[\mathrm{DMSO}]$

\section{Comparison between conventional Fenton and fluidized-bed Fenton processes on DMSO degradation}

Table 3 shows the processes for mineralization of DMSO. In the summary of available DMSO degradation methods, $\mathrm{O}_{3} / \mathrm{UV}$ (Wu et al. 2007) and Fenton process (Park et al. 2001) are the most advantageous. However, $\mathrm{O}_{3} / \mathrm{UV}$ is difficult and expensive to operate as $\mathrm{O}_{3}$ needs to be produced onsite. Moreover, accumulation of ferric hydroxide sludge occurs in Fenton process which would require an additional process for post-treatment (Anotai et al. 2006). The advantages of using the fluidized-bed Fenton processes on DMSO degradation include no extra ferric hydroxide sludges for future treatment, the highest DMSO degradation efficiency, the highest degradation rate, and the lowest $\mathrm{H}_{2} \mathrm{O}_{2}$ consumption. 
(a)

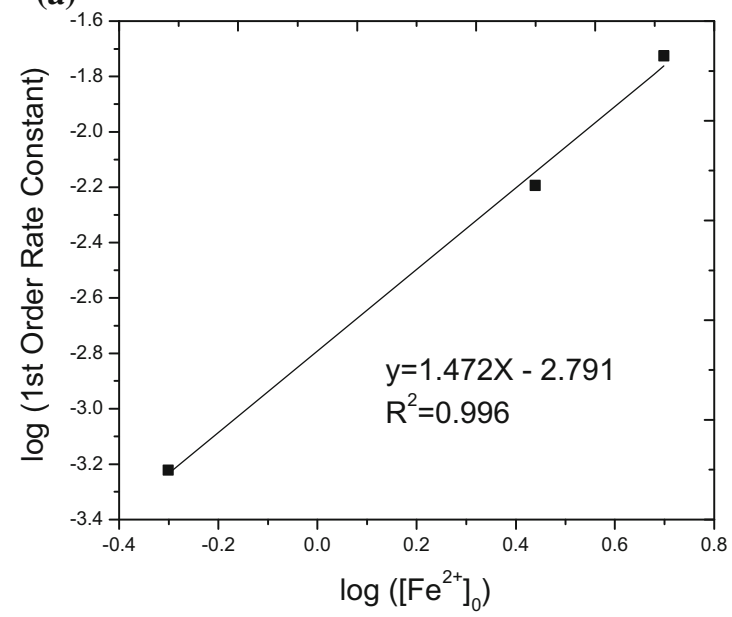

(c)

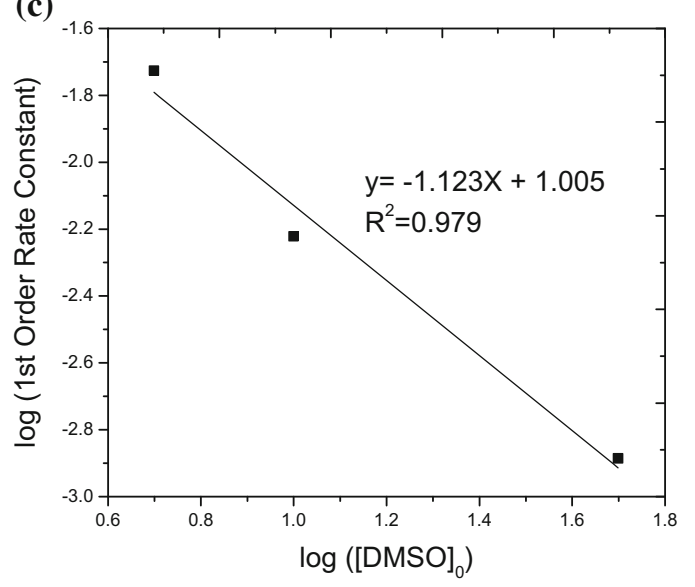

(b)

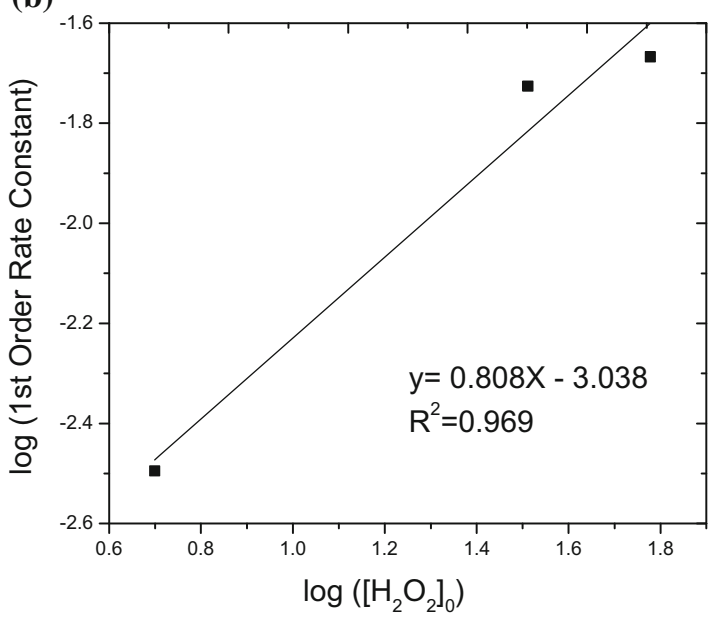

(d)

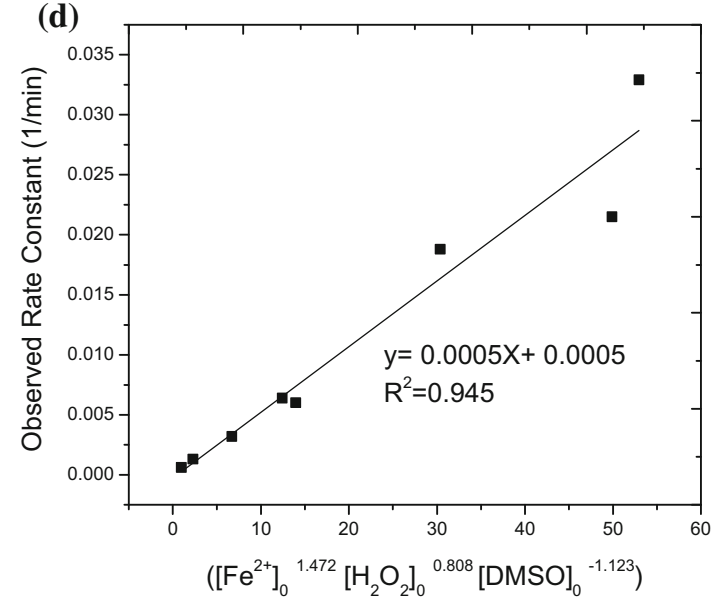

(e)

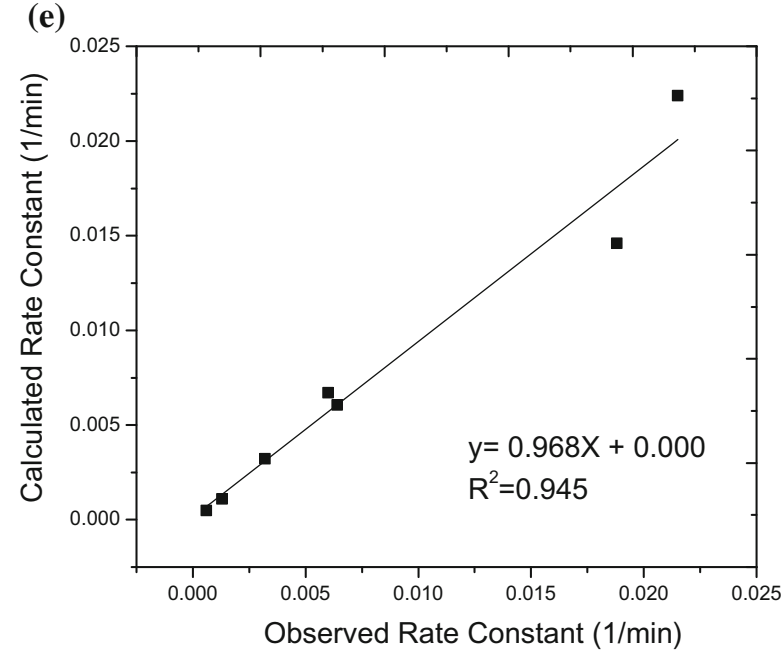

Fig. 7 Linear plots to determine $m$ values for rate constants for the second stage $(\mathbf{a}-\mathbf{c})$; d Linear plot to determine overall rate constant for second stage; e relationship between observed and calculated pseudo-first-order rates of DMSO oxidation: when initial conditions were $\mathrm{pH} \mathrm{3,0.5-7.25} \mathrm{mM} \mathrm{of} \mathrm{Fe}^{2+}, 5-60 \mathrm{mM}$ of $\mathrm{H}_{2} \mathrm{O}_{2}$, and 5-50 mM of DMSO 


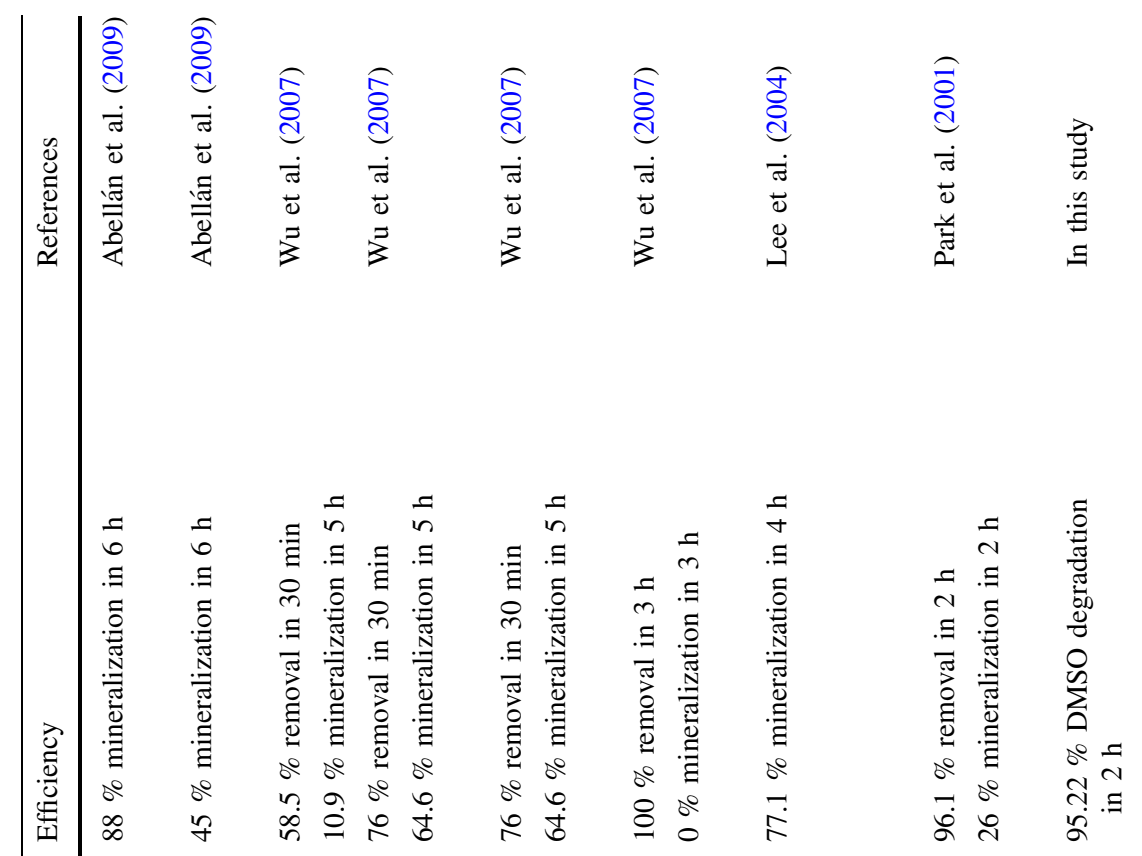




\section{Conclusion}

Fluidized-bed Fenton process is an effective method for the degradation of dimethyl sulfoxide in synthetic wastewater. Parametric study shows that increasing the dose of $\mathrm{Fe}^{2+}$ favored the DMSO degradation. Favorable DMSO degradation was observed in increasing the $\mathrm{H}_{2} \mathrm{O}_{2}$ concentration to a certain extent only due to the scavenging reactions. Furthermore, fluidized-bed Fenton oxidation at $5 \mathrm{mM}$ of DMSO using $68.97 \mathrm{~g} / \mathrm{L}$ of $\mathrm{SiO}_{2}$ worked at initial conditions of $\mathrm{pH} 3,5 \mathrm{mM} \mathrm{Fe}^{2+}$, and $32.5 \mathrm{mM} \mathrm{H}_{2} \mathrm{O}_{2}$.

For initial conditions at $\mathrm{pH} 3,0.5-5 \mathrm{mM}$ of $\left[\mathrm{Fe}^{2+}\right], 5-60$ $\mathrm{mM}$ of $\left[\mathrm{H}_{2} \mathrm{O}_{2}\right]$, and $5-50 \mathrm{mM}$ of [DMSO], the degradation at time $0-3 \mathrm{~min}$ could be described by the pseudo-zeroorder kinetics. The degradation at time 3-120 min, the pseudo-first-order rate could be applied to fit well.

Low sludge production and energy consumption, and high DMSO degradation efficiency are the main advantages of the fluidized-bed Fenton process. The fluidizedbed Fenton process for DMSO degradation was the best technology compared with other AOP technologies, and this system could be applied for real wastewater treatment.

Acknowledgments This work was financially supported by the Ministry of Science and Technology, Taiwan (Grant: MOST 102-2221-E-041-001-MY3).

\section{References}

Abellán M, Dillert R, Giménez J, Bahnemann D (2009) Evaluation of two types of $\mathrm{TiO}_{2}$-based catalysts by photodegradation of DMSO in aqueous suspension. J Photochem Photobiol A 202:164-171

Anotai J, Lu M-C, Chewpreecha P (2006) Kinetics of aniline degradation by Fenton and electro-Fenton processes. Water Res 40:1841-1847

Anotai J, Sakulkittimasak P, Boonrattanakij N, Lu M-C (2009) Kinetics of nitrobenzene oxidation and iron crystallization in fluidized-bed Fenton process. J Hazard Mater 165:874-880

Anotai J, Su C-C, Tsai Y-C, Lu M-C (2010) Comparison of aniline oxidation by electro-Fenton and fluidized-bed Fenton processes. J Environ Eng 137:363-370

Anotai J, Sairiam S, Lu M-C (2011) Enhancing treatment efficiency of wastewater containing aniline by electro-Fenton process. Sustain Environ Res 21:141-147

Bellotindos L, Lu M-H, Methatham T, Lu M-C (2014) Factors affecting degradation of dimethyl sulfoxide (DMSO) by fluidized-bed Fenton process. Environ Sci Pollut Res 21:14158-14165. doi:10.1007/s11356-014-3320-y

Bigda RJ (1995) Consider Fentons chemistry for wastewater treatment. Chem Eng Prog 91:62-66

Brillas E, Sirés I, Oturan MA (2009) Electro-Fenton process and related electrochemical technologies based on Fenton's reaction chemistry. Chem Rev 109:6570-6631

Chemical G (2013) DMSO reaction solvent dimethyl sulfoxide. Technical bulletin reaction solvent dimethyl sulfoxide (DMSO). http://www.gaylordchemical.com/uploads/images/pdfs/literature/ 105B.pdf. Accessed 16 Dec 2014

Chen T, Ni C, Chen J (2003) Nitrification-denitrification of optoelectronic industrial wastewater by anoxic/aerobic process. J Environ Sci Health Part A 38:2157-2167

Chou S, Liao C-C, Perng S-H, Chang S-H (2004) Factors influencing the preparation of supported iron oxide in fluidized-bed crystallization. Chemosphere 54:859-866

Huang C-P, Huang Y, Cheng H, Huang Y-H (2009) Kinetic study of an immobilized iron oxide for catalytic degradation of azo dye reactive black $B$ with catalytic decomposition of hydrogen peroxide. Catal Commun 10:561-566

Hwang S-CJ, Wu J-Y, Lin Y-H, Wen I-C, Hou K-Y, He S-Y (2007) Optimal dimethyl sulfoxide biodegradation using activated sludge from a chemical plant. Process Biochem 42:1398-1405

Karthikeyan S, Anandan C, Subramanian J, Sekaran G (2013) Characterization of iron impregnated polyacrylamide catalyst and its application to the treatment of municipal wastewater. RSC Adv 3:15044-15057. doi:10.1039/C3RA41733F

Kochany J, Lugowski A (1998) Application of Fenton's reagent and activated carbon for removal of nitrification inhibitors. Environ Technol 19:425-429

Koito T, Tekawa M, Toyoda A (1998) A novel treatment technique for DMSO wastewater. IEEE Trans Semicond Manuf 11:3-8

Lee Y, Lee C, Yoon J (2004) Kinetics and mechanisms of DMSO (dimethylsulfoxide) degradation by $\mathrm{UV} / \mathrm{H}_{2} \mathrm{O}_{2}$ process. Water Res 38:2579-2588. doi:10.1016/j.watres.2004.02.028

Lin SH, Lo CC (1997) Fenton process for treatment of desizing wastewater. Water Res 31:2050-2056

Lu M-C, Chen J-N, Chang C-P (1999) Oxidation of dichlorvos with hydrogen peroxide using ferrous ion as catalyst. J Hazard Mater 65:277-288

Masomboon N, Ratanatamskul C, Lu M-C (2009) Chemical oxidation of 2,6-dimethylaniline in the Fenton process. Environ Sci Technol 43:8629-8634

Matira EM, Chen T-C, Lu M-C, Dalida MLP (2015) Degradation of dimethyl sulfoxide through fluidized-bed Fenton process. J Hazard Mater 300:218-226. doi:10.1016/j.jhazmat.2015.06.069

Methatham T, Ratanatamskul C, Lu M-C (2012) Oxidation of 2,4,4' trichloro-2'-hydroxydiphenyl ether (triclosan) by Fenton's reagents with the electrochemical system Sustain. Environ Res 22:371-377

Mollah MYA, Schennach R, Parga JR, Cocke DL (2001) Electrocoagulation (EC)—science and applications. J Hazard Mater 84:29-41

Muangthai I, Ratanatamsakul C, Lu M-C (2010) Removal of 2,4dichlorophenol by fluidized-bed Fenton process. Sustain Environ Res 20:325

Muruganandham M, Swaminathan M (2004) Decolourisation of reactive Orange 4 by Fenton and photo-Fenton oxidation technology. Dyes Pigment 63:315-321

Park S-J, Yoon T-I, Bae J-H, Seo H-J, Park H-J (2001) Biological treatment of wastewater containing dimethyl sulphoxide from the semi-conductor industry. Process Biochem 36:579-589

Soon AN, Hameed B (2011) Heterogeneous catalytic treatment of synthetic dyes in aqueous media using Fenton and photo-assisted Fenton process. Desalination 269:1-16

Tai C, Peng J-F, Liu J-F, Jiang G-B, Zou H (2004) Determination of hydroxyl radicals in advanced oxidation processes with dimethyl sulfoxide trapping and liquid chromatography. Anal Chim Acta 527:73-80

Tang W, Huang C (1996a) 2,4-Dichlorophenol oxidation kinetics by Fenton's reagent. Environ Technol 17:1371-1378

Tang WZ, Huang C (1996b) Effect of chlorine content of chlorinated phenols on their oxidation kinetics by Fenton's reagent. Chemosphere 33:1621-1635 
Tang WZ, Tassos S (1997) Oxidation kinetics and mechanisms of trihalomethanes by Fenton's reagent. Water Res 31:1117-1125

Ting W-P, Lu M-C, Huang Y-H (2009) Kinetics of 2,6-dimethylaniline degradation by electro-Fenton process. J Hazard Mater 161:1484-1490

Urakami T, Araki H, Kobayashi H (1990) Isolation and identification of tetramethylammonium-biodegrading bacteria. J Ferment Bioeng 70:41-44. doi:10.1016/0922-338X(90)90028-U

Wang C-T, Chou W-L, Chung M-H, Kuo Y-M (2010) COD removal from real dyeing wastewater by electro-Fenton technology using an activated carbon fiber cathode. Desalination 253:129-134
Wu JJ, Muruganandham M, Chen S (2007) Degradation of DMSO by ozone-based advanced oxidation processes. J Hazard Mater 149:218-225

Zhang H, Fei C, Zhang D, Tang F (2007) Degradation of 4-nitrophenol in aqueous medium by electro-Fenton method. J Hazard Mater 145:227-232

Zhou M, Yu Q, Lei L, Barton G (2007) Electro-Fenton method for the removal of methyl red in an efficient electrochemical system. Sep Purif Technol 57:380-387 